\title{
Promoting Sustainable Enterprise \& Human Resource Development in Rural Kenya: A Cooperative Approach
}

\author{
Leon C. Prieto \\ Clayton State University \\ James Wairimu \\ Francis Marion University \\ Erastus N. Ndinguri \\ Framingham State University \\ Kenneth K. Kungu \\ Clayton State University
}

\begin{abstract}
There is an urgent need to promote sustainable enterprise and human resource development in order to create thriving rural communities and solve some of the problems facing Kenya such as poverty and under-employment. Rural areas face such challenges as resource constraints, lack of needed infrastructure, inability to attract large employers, availability of local talent, among others, that limit the range of economic development strategies available to rural areas. This paper makes suggestions on how to promote cooperative-modelled entrepreneurial structures, building on the existing tradition of relying on self-help groups and cooperatives for job creation and economic empowerment in rural communities.
\end{abstract}

Keywords: Cooperative Entrepreneurship, Human Resource Development, Sustainable Enterprise

\section{INTRODUCTION}

In Kenya, there is an urgent need to create thriving rural communities via sustainable enterprise and human resource development to solve some of the complex problems facing the rural areas such as poverty and under-employment. According to the Kenya Bureau of Labor Statistics (2018), even though the unemployment rate in Kenya has slightly declined over the years, rural areas recorded higher underemployment rates $(26.6 \%)$ compared to urban areas $(11 \%)$, and urban areas reported higher full-time employment rates $(71.8 \%)$ compared to rural areas $(57.7 \%)$. Further, about $85 \%$ of the unemployed people were below 35 years old.

Pages (2018) identifies some of the challenges faced by rural regions such as resource constraints, lack of needed infrastructure, inability to attract large employers, availability of local talent, among others, that limit the range of economic development strategies available to rural areas. There is an increasing shift in economic development policy to focus more on entrepreneurs and human resource 
development to support job creation in rural areas (Pages, 2018). In Kenya, about 83.6\% of employed people work in the informal sector; and the bulk of this employment, about 12 million people, occurs in micro-enterprises (less than 10 employees) (Kenya National Bureau of Statistics, 2019). Despite these numbers, many people in Kenya can confirm what some experts conclude, that the system of education does not prepare them to become entrepreneurs. It is safe to conclude that entrepreneurship, especially at the micro-enterprise level, is critical in addressing the unemployment challenge in Kenya, especially in rural areas. National and regional government policies should focus on promoting, incentivizing, and supporting scaling of sustainable enterprises in rural Kenya as a way of tackling the myriad of challenges those regions face. This paper makes suggestions on how to promote cooperative-modelled entrepreneurial structures in rural Kenya, building on the existing tradition of relying on self-help groups and cooperatives for job creation and economic empowerment in rural communities.

\section{ENTREPRENEURIAL ENVIRONMENT IN RURAL KENYA}

According to the United Nations Data (2016), Kenya has a population of 47 million people, with only $25.6 \%$ of these individuals living in the urban areas as of the year 2015 . At least $70 \%$ percent live in the rural areas with their main source of income coming from self-employment in subsistence farming (Kate, 2015; Kiiru, 2007). The high rates of unemployment in Kenya have led to the increase in selfemployment especially by women. A significant portion of the Kenyan population consists of the youth, who are defined by the Kenyan constitution as persons whose ages fall in the category of $18-35$ years old (Zepeda et al., 2013). According to the Kenya National Bureau of Statistics (2014), farming contributes about $27.3 \%$ of the GDP. Even though practiced in small-scale, agriculture is the primary business activity for almost all households in rural Kenya. Many of those practicing this are selfemployed in their ancestral lands. Even though historically farming has been synonymous with the elderly people in the village, in more recent times, the youth have embraced farming with interests in application of ICT in agriculture (Mbugua, Irungu, \& Muia, 2015).

Rural entrepreneurship encompasses various practices such as "jua kali" translated to "hot sun" or "working in the blazing heat". Jua kali is a business practice, which involves small, unregistered businesses such as retail stores, which are operated in the neighborhoods (Stevenson \& St-Onge, 2005). There has been a rise in community-based projects among entrepreneurs in Kenya. Various stakeholders such as the United Nations Development Program (UNDP) have collaborated with local communities to help them grow their businesses to alleviate poverty. Such collaborations have come in terms of projects built on the "Nyumba Kumi" initiative; which is a Swahili word for ten huts, which involves the amalgamation of various farmers in groups of tens, whereby they are trained on capacity building (Linna, 2011). Community Power Center/ Energy Kiosk is another example of a project supported by UNDP whereby, small businesses and households can generate cheaper renewable energy that can sustain households and businesses. This is to address the challenge faced by many rural households as it relates to electricity access (Linna, 2011). In a study that focused on community-level entrepreneurial activities in Gichugu constituency in Central Kenya, Lina (2011) found that the Nyumba Kumi initiative had managed to uplift the plight of small agribusiness traders by helping them establish a bulking center, purchase coolers for keeping products fresh, and also invest some money towards promotion of bee-keeping. As far as the energy kiosks were concerned, their establishment led to new entrepreneurial opportunities such as mobile phone charging kiosks, barbershops, cyber cafes, flour millings, among others (Linna, 2011). Other community-based projects included chamas, (a Swahili word that means 'togetherness) a microsavings group that involves pooling of funds that are given to every member in a merry-go round fashion. People often use these funds to make personal investments (Voice of America, 2015).

Entrepreneurs are facing financial challenges, and hurdles within the regulatory environment. In a study that focused on rural youth entrepreneurship in East Africa (2012), those interviewed cited stringent rules by financial institutions made it difficult for them to access loans to start or expand their businesses. Most lenders required them to have collateral in the form of valuable assets. More than two thirds of those studied acknowledged that they funded their startups from personal savings or loans from family 
members (Namatovu et al., 2012). Some also cited difficulties registering their businesses due to the lengthy time it took to acquire a business permit.

However, there has been some government effort aimed at encouraging and supporting entrepreneurship, especially among the youth. The Vision 2030, an overarching government planning document, places emphasis on the need to support entrepreneurial activity to grow the economy and make Kenya a middle-income earning economy by the year 2030 (Kenya Vision, 2030). One of the ways of achieving this is through a program known as "Uwezo Fund", which means "Capacity Fund" or empowerment. It was established as a way of providing loans to aspiring entrepreneurs in three categories; Women, youth, and persons with disabilities who have viable start up ideas (Uwezo Oversight Board, 2019). Aspiring youth and women entrepreneurs form groups in which they apply for the loans, which range from KES (Kenyan Shilling) 50,000 (\$500 US dollars) to KES 500,000 (\$5,000 US dollars) and after approval are disbursed into the group accounts through the Constituents offices (Uwezo Oversight Board, 2019).

Other private stakeholders have also chipped in to provide small loans such as M-shwari, a paperless banking service provided by Safaricom, the largest telecommunication firm in Kenya "Shwari" is a Swahili word which means calm). It is a mobile account that allows mobile subscribers to save money through their mobile phone accounts and access loans of up to KES 100,000 payable in 30 days with no interest charged, only a 7.5\% loan facilitation fee is required (Cook \& McKay, 2015). This has enabled small business owners to access quick funds especially with the low number of financial centers in the rural areas. Other government approaches aimed at promoting entrepreneurship include streamlining its service delivery to make it easy for business owners to access services such as business registration with greater ease. This was accomplished via the decentralization of services from central government, to offices in the counties known as huduma (service) centers (Softkenya, 2016). This improved Kenya's ease of doing business (Business Daily, 2015). An online version of huduma centers was also established to help people access online government services.

\section{Challenges Facing Kenya's Rural Communities}

Rural communities in Kenya are faced with challenges such as unemployment, where university and college graduates flood the insufficient job market. According to a report by the World Bank Group (2016), Kenya has the highest youth unemployment rate in sub-Saharan Africa. As of the year 2013, 3 million youths had attained the working age, and only 2.6 million jobs had been created in the economy (World Bank Group, 2016). This indicates an unemployment gap. According to the Kenya National Bureau of Statistics, university enrollment as of the year 2013 stood at 210,338. This represents $80.6 \%$ male, while $19.4 \%$ were female. All these youths will eventually graduate and enter the job market, which is hardly experiencing growth in terms of new employment opportunities. There is a high demand for white collar jobs, as the graduates, who are mostly young people find it unattractive to work in sectors such as agriculture (Irungu, Mbugua, \& Muia, 2015).

Another challenge is poor infrastructure. This is paramount to the success of any form of business activity since it affects logistics, access to markets, and ultimately affects the cost structure of any enterprise. Farmers in the rural areas face the challenge of bad roads and the terrain, which makes it difficult and expensive to transport goods from their farms to the marketplace. On a positive note, the government via the Agricultural Finance Corporation, made strides improving service delivery through the web. They communicate important farming information to the farmers through text messages and their interactive website, whereby agricultural information about production, suppliers, and markets is also available. Different stakeholders have also embraced digital marketing through mobile apps and social media platforms such as 'mkulima young', whereby young entrepreneur farmers are able to share photos/ videos of their farms and consult the more experienced customers (Irungu, Mbugua, \& Muia, 2015). However, the farmers in the remote areas have a challenge of accessing such services due to limited or a complete lack of mobile and bandwidth signals. There is need for fast and accessible internet and broadband connectivity to achieve efficiency in information relay. 
Rural areas are also faced by drug abuse and alcohol challenges. According to a report, alcohol abuse leads the way by $12.2 \%$ among individuals aged between 15-65 years old (Kamenderi et al. 2017). Alcohol abuse negatively affects work force productivity since most of the affected individuals are the youth (Githui, 2011; Kaithuru and Stephen, 2015). This may have devastating effects on youth employment as the report cites areas like Eastern, Rift Valley, Nyanza, and Central provinces, where agriculture is the major form of employment. Such developments lead to the sale of rural ancestral land to property developers, and without adequate financial knowledge, farmers may end up squandering their money, and eventually spiral into poverty (Njagi, 2018).

There is also the issue of education and training as it relates to rural entrepreneurship. According to the Rural Youth Entrepreneurship research in East Africa (Namatovu et al., 2012), one third of the population has completed lower secondary education. This number is relatively high for a developing country and it can be attributed to the free and compulsory primary education introduced in 2002 by the government of the day. However, the education system in Kenya is not well equipped to help the youth become entrepreneurial, especially those who do not make it to post-secondary education. This has led to poverty, which has resulted to indulgence into petty crimes in the quest for survival. The education system should be structured in a way that prepares individuals to sustain themselves through skills learned from school. Entrepreneurship education in form of technical and financial training, as well training in social innovation should be included in the curriculum and in this way, unemployment can be reduced significantly (Nelson \& Johnson, 1997). This can lead to the creation of sustainable entrepreneurial ecosystems that can enrich rural communities.

\section{RURAL ENTREPRENEURSHIP \& NATIONAL HUMAN RESOURCE DEVELOPMENT}

To overcome the challenges emanating from unemployment, inadequate education, limited infrastructure, and drugs; empowerment of the human capital is needed in rural Kenya. This can be done by investing, rebuilding, customizing skills (Lepak \& Snell, 1999) and deploying technology that can be used to develop human capital development (Waldeck \& Leffakis, 2007). To enhance the growth of entrepreneurship efforts by the government and the growth of micro-saving association in rural areas this paper proposes development of cooperative modeled entrepreneurial structures. The structures can capture the synergies brought about by individual actors in the rural areas (via Chamas \& Nyumba Kumi), government initiatives (via Vision 2030, \& Huduma Centers \& Uwezo Fund) and the private sector (via M-Swari).

The conventional definition of cooperatives is an organization that is collectively owned either by its members or by its suppliers (Hansmann, 2014). They respond to a specific problem or opportunity and are organized as a response to provide a needed service (United States Department of Agriculture, 2015). In Kenya, the cooperative movement has been largely focused on agriculture sector dating back to the time of colonialism (Gyllstrom, 1991). The first cooperative society was established in 1908, and by 2015, there were 19,200 registered co-operative enterprises with a total membership of 14 Million members, which cut across all sectors of the economy, both formal and informal. They serve a wide variety of purposes such as marketing agricultural products, savings and credit, and investments (Ministry of Industry, Trade and Co-operatives., 2017). The most common form of cooperative association in Kenya is a "chama" which is defined as:

"Any collection of individuals or legal persons in any form whatsoever including but not limited to: societies registered under the Societies Act, Partnerships and Limited Liability Companies, whose objective is the pooling together of capital or other resources with the aim of using the collated resources for investment purposes (Kenya Association of Investment Groups, 2014, p. 11).”

It is estimated that there are 300,000 chamas in Kenya, and they take various forms such as village, clan, and welfare associations; micro-savings and credit groups; self-help groups; small co-operative 
societies (SACCO), general (business) partnerships, and limited liability companies (Kenya Association of Investment Groups, 2014). Kenya's Cooperative Development Policy identifies principles, which guides the operation of cooperatives. These include, open and voluntary membership, democratic member control, member economic participation, autonomy and independence, and concern for the community (Ministry of Industry, Trade and Co-operatives., 2017).

On a broader scale, cooperatives have significantly contributed to the mobilization and distribution of financial capital; created employment and income-generating opportunities and constituted a forum for education and training (Wanyama, Develtere, \& Ignace, 2008). In rural Kenya, cooperatives are involved in the informal economy where savings and credit activities are their main role (Softkenya, 2016). Entrepreneurship as an organized activity has mainly been carried out by micro finance groups as well as government initiatives (Voice of America, 2015; Softkenya, 2016). To improve rural entrepreneurial growth, stronger structures that support entrepreneurial activities are needed. This paper suggests steps rural entrepreneurs can take to build entrepreneurial cooperatives, which in turn can provide support for their entrepreneurial activities. This paper adapts the three steps for forming cooperatives by the United States Department of Agriculture model to fit the Kenyan context. Even though the steps outlined were applicable to the United States, the model can be customized to fit a developing country like Kenya.

\section{CONCEPTUAL MODEL}

To capture the needs of different rural areas in Kenya the first step would be to disseminate information on the idea of forming cooperatives in rural Kenya. Using government platforms (for example Huduma center), local media (print media, radio stations and television) and local leaders (clergy and elders), the government can disseminate information on what an entrepreneurial cooperative entails and ways it can help local entrepreneurs. Huduma centers are government run centers that give citizens access integrated public services via their phones, computers, and personal digital assistants (Abdalla et. al., 2015). Most Kenyans visiting Huduma centers have expressed satisfaction with the services provided. This is evidenced by $90 \%$ of customer issues being resolved, and most users indicating they would recommend the centers (Abdalla et. al., 2015). Such positive support can be harnessed as a resource to disseminate information through the centers. In addition, the media plays an important role in information dissemination to the public. The media has a strong influence on perceptions, beliefs, and attitudes of society (Koltay, 2011). In the past, the Kenyan media has been successfully used to disseminate information on initiatives such as family planning (Westoff \& Rodríguez, 1995), and AIDs prevention (Agha, 2003). Given this success, the media becomes a critical partner in informing the population about the cooperative idea.

The second step is identifying the economic need (United States Department of Agriculture, 2015). "Chamas" and "Nyumba Kumi" are a good starting point to organize meetings to identify needs, and whether there is an interest to start a cooperative. The Kenya National Bureau of Statistics, \& Financial Sector Deepening program (2016) indicates that a large percentage of Kenyan adults use an informal financial service. These informal services have increased at a rate of over ten percent between 2006 and 2016 (Kenya National Bureau of Statistics, \& Financial Sector Deepening, 2016). Once the meetings are organized and the members attending the "Chamas" and "Nyumaba Kumi" get-togethers show interest, a committee is selected to spearhead the initiative. The committee conducts due diligence on the economic need, and this is done by spearheading a member-user analysis (to learn more about the members). Also, initial market analysis (understand the marketplace the cooperative will operate in), conducting a feasibility (checking whether the idea is feasible, based on well-determined assumptions, researched information, and the member-use and initial market analysis information) and eventually preparing a business plan (United States Department of Agriculture, 2015).

The third step involves implementing the plan. The committee drafts legal documents that seek to have them recognized as a cooperative. The committee engages legal assistance who help in ensuring that the right procedures are followed (United States Department of Agriculture, 2015). This stage also entails training of members on how they can utilize the cooperative society and their rights as members. Using 
chamas and the local media as communication tools, members can understand what the cooperatives will do as well how they can use them efficiently. Figure 1 below depicts the proposed Rural Kenya Entrepreneurial Cooperative Model.

FIGURE 1

\section{RURAL KENYA ENTREPRENEURIAL COOPERATIVE MODEL}

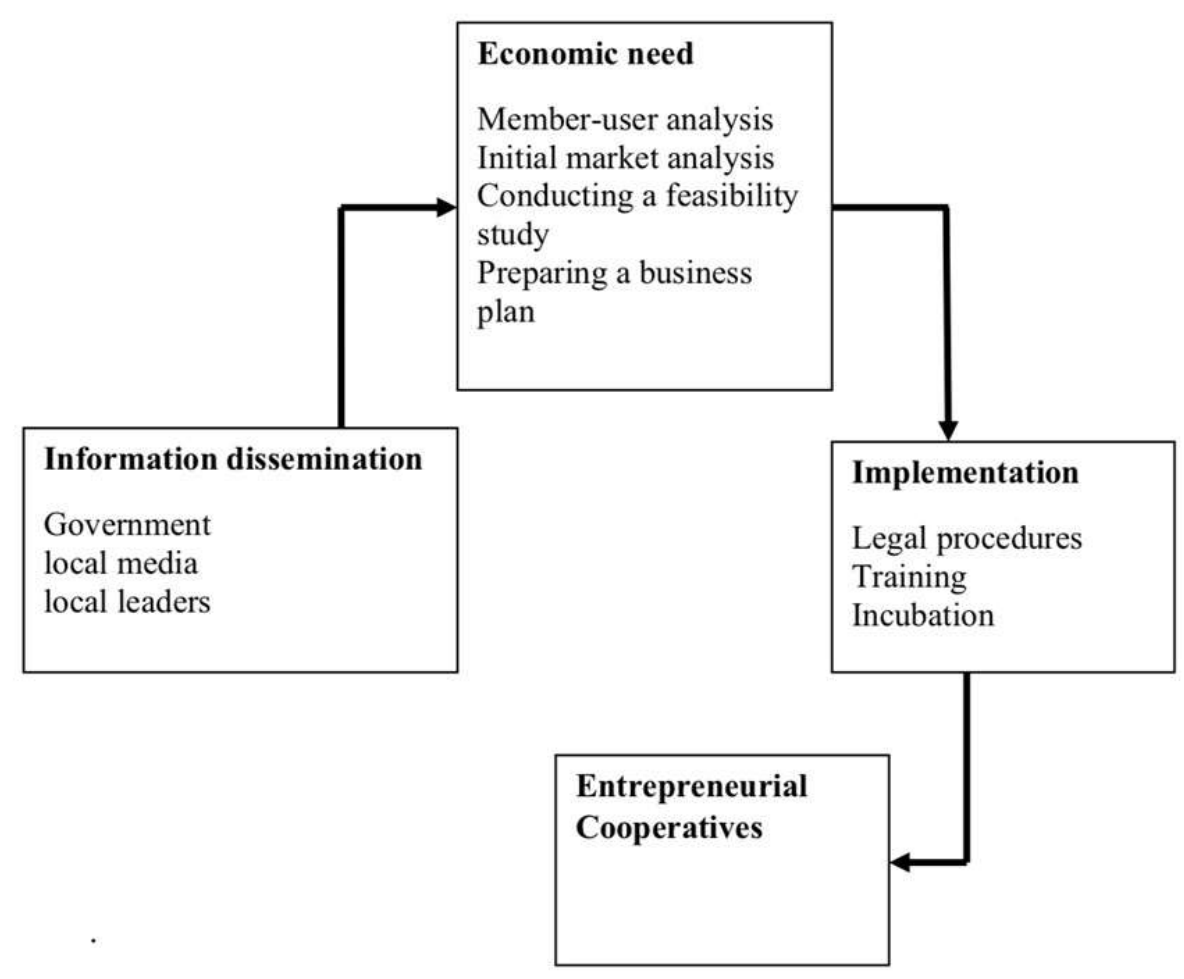

The model above depicts the process of forming an entrepreneurial cooperative in rural Kenya. The connection between government and informal sectors can create a synergy that can accelerate the acceptance and use of entrepreneurial cooperatives.

\section{Human Resource Development \& Cooperatives}

Cooperative entrepreneurship has tremendous potential in promoting job creation and economic development in rural areas. To realize this potential, there should be better collaboration between entrepreneurial development initiatives and workforce/talent development initiatives (Dabson, 2018; Pages, 2018). In Kenya, the national and county government, chamber of commerce, and the private sector play an important role in creating policies, providing resources and creating an enabling environment for entrepreneurs to initiate ventures and grow them. However, they need to work more closely with institutions such as high schools, technical colleges, universities, and other community-based organizations that are responsible for fostering, training and developing emerging entrepreneurs especially in rural areas where there is a greater need. The main goal of workforce development in rural contexts should be to afford everyone resources and opportunity to improve their economic circumstances through education and skill development (Dabson, 2018). There should be an integration of workforce development and entrepreneurial development in policy and practice. There are several ways in which workforce development initiatives can contribute to the development of cooperative entrepreneurial ventures in Kenya at each step in the Entrepreneurial Cooperative Model.

The first step is disseminating information about cooperatives in rural Kenya. Beyond using government platforms, local media, and elders to disseminate information about entrepreneurship, 
cooperative entrepreneurship should be promoted as a viable alternative to formal employment, and training on how to establish cooperative entrepreneurial ventures provided by various institutions involved in workforce development such as primary/high schools, technical colleges, universities, and civic and community-based organizations. Promoting self-employment and providing training on how to pursue entrepreneurship is critical in developing a pipeline of entrepreneurial talent (Pages, 2018). According to the Kenya National Bureau of Statistics (2018) the largest unemployment rate was in the "20-24" age cohort, at $19.2 \%$. Therefore, beginning this promotion and training in cooperative entrepreneurship in primary and high schools can help address the huge problem of youth unemployment in Kenya. High schools should consider incorporating cooperative entrepreneurship in the curriculum. Technical colleges and universities should also consider offering courses and minors in cooperative entrepreneurship. Lastly, the government could prioritize funding civic and community-based organizations that operate in and have outreach efforts in rural communities to enable them to promote and train people in cooperative entrepreneurship in rural areas.

In identifying economic need, workforce development professionals can aid entrepreneurs by either providing training and/or coaching services. According to Pages (2018) rural regions suffer from an overreliance on a few core industries primarily in agriculture and extraction. In a study of non-farm entrepreneurship in six countries in rural sub-Saharan Africa, Nagler and Naudé (2017) found that at least $42 \%$ of rural households operated a non-farm enterprise, mostly in easier-to-enter activities such as sales and trade. Workforce development players can help rural entrepreneurial groups diversify their economic activities through coaching them to consider investing in emerging sectors; training and equipping them with skills to take advantage of emerging opportunities in new sectors; and equipping entrepreneurs to create new industry clusters (Pages, 2018). Workforce development partners can provide training, coaching and other important components unique to forming a cooperative venture such as member-user analysis, conducting feasibility studies, and preparing business plans.

At the implementation stage, cooperative entrepreneurial ventures will need training and coaching on such aspects as incorporation/registration, funding, starting up, and scaling. Workforce development professionals can also provide cooperatives with the necessary training on the importance of registering their cooperative ventures, selecting the best registration vehicles based on the purposes of their venture, and the various resources available for them. This is especially important in Kenya where it is estimated that 5.86 million businesses are unlicensed compared to 1.56 million licensed businesses (Kenya National Bureau of Statistics, 2016). Technical colleges, universities, and community-based organizations should consider setting up incubators for sustainable cooperative ventures where they can provide much needed training, consultation, coaching, and technical assistance to help they grow and scale. Those initiatives have the potential to transform communities into sustainable entrepreneurial ecosystems.

\section{CONCLUSION}

The main contribution of this article is to provide a framework that can be adapted in the rural Kenyan context to aid in the formation of cooperative enterprises. This can lead to the creation of sustainable rural communities, and the reduction of poverty and unemployment, which are aligned with the United Nations sustainable development goals. Bold measures need to be taken that incorporate a bit of old with the new. Economic cooperation has existed in Kenya since the pre-colonial days, and by incorporating some of the older traditions with the formal cooperatives, communities can take control of their destiny, and solve their challenges via the creation of cooperative enterprises. Social innovation is also possible within the cooperative business model. Phills (2008) stated that social innovation is a novel solution to a social problem that is more effective, efficient, sustainable, or just than existing solutions. Cooperatives can play a significant role in promoting entrepreneurship in Kenya and solving wicked problems that exist in rural communities. Human resource development with an emphasis on cooperative enterprise education and training while utilizing local traditions of economic cooperation has the potential to create positive lasting change that can revitalize rural communities. 


\section{REFERENCES}

Abdalla, A.G., Kiragu, J.K., Waswa, F.A., Ono, F.T., Kariuki, J.W., \& Ikua D.M. (2015). Effect of Huduma Centers (One Stop Shops) in Service Delivery- A Case Study of Mombasa Huduma Centre. International Journal of Academic Research in Business and Social Sciences, 5(6), 1-16.

Agha, S. (2003). The impact of a mass media campaign on personal risk perception, perceived selfefficacy and on other behavioral predictors. AIDS CARE, 15(6), 749-762.

Business Daily. (2015). Huduma centres lift Kenya up business friendliness rankings. Retrieved September 28, 2016, from http://www.businessdailyafrica.com/Huduma-centres-Kenya-businessfriendliness-rankings/-/539546/2933848/-/14hcwar/-/index.html.

Cook, T., \& McKay, C. (2015). How M-Shwari works: The story so far. Consultative Group to Assist the Poor (CGAP) and Financial Sector Deepening (FSD).

Dabson, B. (2018). The Rural Dimensions of Workforce Development, In S. Andreason, T. Greene, H. Prince, \& C.E. Van Horn (Eds.), Investing in America's Workforce: Improving Outcomes for Workers and Employers, Volume 2: Investing in Work. (pp. 183-194). Kalamazoo MI: W.E. Upjohn Institute for Employment Research.

Githui, D.M. (2011). Drinking Culture and Alcohol Management in Kenya: An Ethical Perspective. European Journal of Business and Management, 3(4), 132, 145.

Gyllstrom, B. (1991). State Administered Rural Change: Agricultural Cooperatives in Rural Kenya. London: Routledge.

Hansmann, H. (2014). All firms are cooperatives - and so are governments. Journal of Entrepreneurial and Organizational Diversity, 2(2), 1-10.

Irungu, K.R.G., Mbugua, D., \& Muia, J. (2015). Information and Communication Technologies (ICTs) Attract Youth into Profitable Agriculture in Kenya. East African Agricultural and Forestry Journal, 81(1), 24-33.

Kaithuru, P.N., \& Stephen, A. (2015). Alcoholism and its Impact on Work Force: A Case of Kenya Meteorological Station, Nairobi. J Alcohol Drug Depend, 3(192), 2-4.

Kamenderi, M., Muteti, J., Okioma, V., Kimani, S., Kanana, F., \& Kahiu, C. (2017). Status of Drugs and Substance Abuse among the General Population in Kenya. African Journal of Alcohol \& Drug Abuse, (1) 54-59

Kenya Association of Investment Groups. (2014). The chama handbook (2nd ed.). Nairobi: Raspberry Haven Ltd.

Kenya National Bureau of Statistics, \& Financial Sector Deepening. (2016). 2016 FinAccess Household Survey. Nairobi, KE: Author. Retrieved from http://fsdkenya.org/wpcontent/uploads/2016/02/The-2016-FinAccess-household-survey-report1.pdf

Kenya National Bureau of Statistics. (2014). Facts and Figures 2014. Nairobi: Kenya National Bureau of Statistics.

Kenya National Bureau of Statistics. (2016). Micro, Small and Medium Establishment (MSME) Survey: Basic Report. Nairobi: Kenya National Bureau of Statistics.

Kenya National Bureau of Statistics. (2018). 2015/16 Kenya Integrated Household Budget Survey (KIHBS): Labor Force Basic Report. Nairobi: Kenya National Bureau of Statistics.

Kenya National Bureau of Statistics. (2019). Kenya economic survey 2019. Nairobi: Kenya National Bureau of Statistics.

Kenya Vision 2030. (n.d.). Retrieved September 28, 2016, from http://www.vision2030.go.ke/aboutvision-2030/

Kiiru, J.M. (2007). Microfinance, entrepreneurship and rural development: Empirical evidence from Makueni district, Kenya. In Global Poverty Research Group (GPRG) Conference. Oxford University, UK.

Koltay, T. (2011). The media and the literacies: media literacy, information literacy, digital literacy. Media, Culture \& Society, 33(2) 211-221 
Lepak, D.P., \& Snell, S.A. (1999). The human resource architecture: toward a theory of human capital allocation and development. Academy of Management Review, 24(1), 31-48. doi:10.5465/AMR.1999.1580439.

Linna, P. (2011). Community-level entrepreneurial activities: Case study from rural Kenya. Int J Bus Public Manage, 1, 8-15.

Ministry of Industry, Trade and Co-operatives. (2017). Cooperative Development Policy: Promoting Cooperative Enterprises for Industrialization. Nairobi: Ministry of Industry, Trade and Cooperatives.

Nagler, P., \& Naudé, W. (2017). Non-farm entrepreneurship in rural Sub-Saharan Africa: new empirical evidence. Food Policy, 67, 175-191

Namatovu, R., Dawa, S., Mulira, F., Katongole, C., \& Nyongesa, S. (2012). Rural Youth Entrepreneurs in East Africa: A view from Uganda and Kenya. ICBE-RF Research Report No. 32, 12.

Nelson, R.E., \& Johnson, S.D. (1997). Entrepreneurship education as a strategic approach to economic growth in Kenya. Journal of Industrial teacher education, 35, 7-21.

Njagi, K. (2018). Property boom in rural Kenya creates 'poor millionaires. Retrieved March 7, 2020 , from https://www.reuters.com/article/kenya-property-farming/feature-property-boom-in-ruralkenya-creates-poor-millionaires-idUSL5N1V42GP

Pages, E.R. (2018). Igniting Rural Entrepreneurship: Where Do Workforce Development Programs Fit In?, In S. Andreason, T. Greene, H. Prince, \& C.E. Van Horn (Eds.), Investing in America's Workforce: Improving Outcomes for Workers and Employers, Volume 2: Investing in Work (pp 213-225). Kalamazoo MI: W.E. Upjohn Institute for Employment Research.

Phills, J.A., Deiglmeier, K., \& Miller, D.T. (2008). Rediscovering Social Innovation. Stanford Social Innovation Review, 35(4), 34-43.

Schecter, K. (2015). In Kenya, Encourage Rural Entrepreneurship. Retrieved September 10, 2016, from http://www.worldpolicy.org/blog/2015/09/14/kenya-encourage-rural-entrepreneurship

SoftKenya. (2016). Huduma Centre Kenya - Huduma Kenya Services, Centers and Contacts. Retrieved September 28, 2016, from http://softkenya.com/huduma/

Stevenson, L., \& St-Onge, A. (2005). Support for growth-oriented, women entrepreneurs in Kenya. International Labour Organization.

UN Data. (n.d.). Retrieved September 10, 2016, from http://data.un.org/CountryProfile.aspx?crName=kenya

United States department of agriculture model. (2015). Rural Development Business and Cooperative Programs (Report No7). Washington, DC: Author.

Uwezo Oversight Board. (2019). Retrieved September 28, 2019, from http://www.uwezo.go.ke/

Voice of America. (2015). Chama - A Driver of the Non-Formal Economy in Kenya. Retrieved September 28, 2016, from http://learningenglish.voanews.com/a/chama-driver-nonformal-economykenya/2866813.html

Waldeck, N.E., \& Leffakis, Z.M. (2007). HR perceptions and the provision of workforce training in an AMT environment: An empirical study. The International Journal of Management Science, 35(2), 161-172.

Wanyama, F.O., Develtere, P., \& Ignace, P. (2008). Encountering the Evidence: Cooperatives and Poverty Reduction in Africa. Working Papers on Social and Co-operative Entrepreneurship WPSCE 08-02. Retrieved from https://ssrn.com/abstract $=1330387$ or http://dx.doi.org/10.2139/ssrn. 1330387

Westoff, C.F., \& Rodríguez, G. (1995). The mass media and family planning in Kenya. International Family Planning Perspectives, 21(1), 26-36.

World Bank Group. (2016). Kenya Country Economic Memorandum: From Economic Growth to Jobs and Shared Prosperity. Retrieved September 28, 2016, from http://documents.worldbank.org/curated/en/763771468197384854/pdf/103822-WP-KenyaCountry-Economic-Memorandum-PUBLIC.pdf

Zepeda, E., Leigh, F., Ndirangu, L., Omollo, J., \& Wainaina, S. (2013). Kenya's Youth Employment Challenge. United Nations Development Programme. 